\title{
Intuitive Self-development as an Important Factor af the Spiritual and Mental Self-healing of an Individual and Society
}

\author{
Tamara Tyurina ${ }^{1}$, Sofiya Stavkova ${ }^{1}$ \\ ${ }^{1}$ Lviv Polytechnic National University, Lviv, Ukraine
}

Introduction. The modern school of all levels is aimed primarily at the development of the mechanisms of the left cerebral hemisphere, that is rational, logical thinking, analytical perception of reality. As a result, a person with technocratic thinking, pragmatic, consumer attitude towards the world is brought up, that leads to disharmony of an individual with his/her own nature and environment. The actualization of the intuitive potential of the individual is aimed at the hearty, spiritual and mental perception, cognition and interaction with the world, formation of a sense of unity, connection with the environment, promotes the harmonization of the individual's relations with oneself and the world, his/her spiritual and mental improvement.

The objective of the article: to show the role and significance of intuitive-spiritual self-development for the spiritual and mental health of the individual.

Methodology: the article uses theoretical analysis of scientific journals over the last 5-10 years, recommended by the Ministry of Education and Science of Ukraine, as well as other scientific sources.

Results and Discussion. According to V. Vernadsky's teachings and modern informational and energy paradigm, an Individual - Society - Earth - Universe is a solid cosmoplanetarian organism that represents a coherent informational and energy system, in which all the elements closely interact, interconnect and are mutually determined. An individual in this context is interpreted as an active component of the Universe, the cosmoplanetary phenomenon, an open bio-informational and energy system, which, being in a constant information-energy interchange and interconnections with the cosmoplanetary world, at the same time it is a "transmitter" and a "receiver" and, accordingly, a "carrier" of information about the surrounding reality, despite whether he/she is conscious of this process or not. Modern scholars consider the human organism to be an information and energy transmitting biological antenna, which practically constantly receives and transmits information and energy signals. And if a person has reached the appropriate level of spirituality, lives in harmony with himself/herself and the cosmoplanetary world, he/she activates intuition and becomes capable at a conscious level to interact with the world applying in formation and energy (Vernadsky, 1991; 2002).

Contemplating this way, intuition can be interpreted as a special mental state of a highly spiritual person, in which he/she deliberately enters into information-energy contact with any object of the Universum - the physical or the subtle world, cosmos "connects" to its information field, "reads out", "decrypts" and analyzes the necessary information. This information-energy interaction is perceived by a person as the process of connection, merging with the object being studied, which enables instant cognition of its true essence.

Disclosure and development of intuition are closely interrelated with the individual's spirituality development level. The higher this level is, the more clearly the individual's ability to intuit self-knowledge and express cognition, since intuition is connected with the spiritual-mental, information-energy component of a personwith his/her biofield.

It is the level of spirituality that identifies the strength of personal biofield, - the information and energy framework, which ensures a complete and adequate information-energy interchange and interaction of an individual with the cosmoplanetary world in the scale of the planet and the Universe: with other people, with the Earth, the Cosmos, the Universe, the Sun, the planets, and the stars (Kaznacheev, Spirin, 1991).

Consequently, according to the modern information-energy paradigm, a person is seen as a creative informational and energetic substance of the Universe, which is associated with the whole Universe at the spiritual and intuitive level.

The spiritually intuitive individual is characterized by an inner harmony, peace and independence from external circumstances, adequate self-esteem and self-sufficiency, self-confidence and self-respect, openness to people and the whole world, tolerance, ability to heroically act in the name of a high idea and self-sacrifice, tolerance, goodwill, empathy, as well as the ability to love, kindness, compassion, willingness to help, desire to live in harmony with oneself and the world, to harmonize relationships in the information and energy system (Tyurina, 2017). An Individual - Society - Earth - the Universe, that is, spiritual and mental health, which is transmitted on the information and energy level both to people and the environment, promotes the harmonization and spiritualization of society and the world.

Conclusions: Spiritually-intuitive self-development of a person leads to overcoming the subjective isolation of people, formation of a sense of general unity, kinship with all surrounding space, forms a life-creating unity, consonance and co-development of an individual with the cosmoplanetary world. So, developing spiritually and intuitively, the individual contributes in this way both to his or her own spiritual and mental self-healing and to the spiritual healing of the society as a whole, because at the information-energy level we are the only system, all components of which are closely interconnected and mutually interconnected. 
Practical value. The findings of the research could be used in the development of individual plans, training programs aimed at personal and spiritual self-development of the student's personality, lecturing students on medical psychology, social pedagogy, philosophy, etc.

Keywords. individual as an informational and energy system, intuition, spirituality, spiritual and mental health

\section{References}

Vernadsky V.I. (2002). Biosphere and noosphere. M.: Rolf, 576 p.

Vernadsky V.I. (1991). A few words about the noosphere // Scientific thought as a planetary phenomenon. M.: Science, P. 235-243.

Kaznacheev V.P., Spirin E.A. (1991). Cosmoplanetary Phenomenon of a Human: Problems of Comprehensive Study. Novosibirsk: Science. Siberian Branch, 304 p.

Tyurina T. G. (2017). The upbringing of students' spirituality in the noosphere dimension: monograph. - Lviv: Lviv Polytechnic Publishing House, 284 p. 